\title{
DIAGNÓSTICO DO PROCESSO DE COLETA E COMERCIALIZAÇÃO DE RECICLÁVEIS REALIZADO POR CATADORES NA CIDADE DE PASSO FUNDO/RS (BRASIL)
}

\section{DIAGNOSIS OF RECYCLABLE WASTES COLLECTED BY SCAVENGERS IN THE CITY OF PASSO FUNDO/RS (BRAZIL)}

\section{Aline Pimentel Gomes', Adalberto Pandolfo², Dayane Muhammad $^{3}$, Elvis Carissimi ${ }^{4}$, Marcele Salles Martins ${ }^{5}$}

\author{
${ }^{1}$ Engenheira Civil. Mestre em Engenharia. Professora da Universidade de Passo \\ Fundo. E-mail: alinegomes1977@hotmail.com \\ ${ }^{2}$ Engenheiro Civil. Doutor em Engenharia de Produção. Professor da Universidade de \\ Passo Fundo. E-mail: adalbertopandolfo@hotmail.com \\ ${ }^{3}$ Graduanda em Engenharia Ambiental pela Universidade de Passo Fundo. E-mail: \\ dayaninham@gmail.com \\ ${ }^{4}$ Engenheiro Civil. Doutor em Engenharia de Minas, Metalúrgica e de Materiais. \\ Professor da Universidade Federal de Santa Maria. E-mail: ecarissimi@gmail.com \\ ${ }^{5}$ Arquiteta e Urbanista. Mestre em Engenharia. Professora da IMED- Complexo de \\ Ensino Superior Meridional. E-mail: marcelesalles@yahoo.com.br
}

\begin{abstract}
RESUMO
Este artigo tem como objetivo diagnosticar o processo de coleta e comercialização de resíduos recicláveis, realizado pelos catadores da cidade de Passo Fundo/RS. Dados referentes ao trabalho dos catadores de recicláveis foram obtidos em entidades assistenciais ligadas aos catadores, com os sucateiros da cidade e com os próprios trabalhadores por meio de entrevistas, formulários e observações diretas. Os resultados demonstram que existem cerca de 1.500 catadores na cidade, incluindo jovens e crianças, $97 \%$ trabalham de forma autônoma, em condições precárias e têm que percorrer grandes distâncias para realizar a catação na área central da cidade. Os catadores possuem baixa escolaridade, sendo que $24 \%$ são analfabetos, a maioria tem a atividade de catação como única fonte de renda e $92 \%$ recebem um valor inferior ao salário mínimo. Além disso, o grande número de atravessadores e a grande distância até a indústria de reciclagem fazem com que os preços pagos pelos recicláveis aos catadores sejam baixos.
\end{abstract}

PALAVRAS-CHAVE: Resíduos sólidos urbanos. Recicláveis. Catadores. Coleta informal.

\footnotetext{
ABSTRACT

This paper aims to diagnose the recyclable wastes collected by scavengers in the city of Passo Fundo/RS. The data regarding the collection of recyclables were obtained from the collectors
} 
themselves, to scrap dealers operating in the city and through social entities to which these workers are linked. The research instruments were interviews, forms and direct observations. The results show there are about 1.500 recyclable collectors in the city, including youth and children, $97 \%$ work independently, in precarious conditions, they have to travel long distances to collect recyclable waste in the downtown area. The collectors have low education level, while $24 \%$ are illiterate, most of them have the collecting activity as the only source of income and $92 \%$ receive a value below the minimum wage. The price of recyclable wastes paid to collectors is low due the large number of middlemen and the long distance to the recycling industry.

KEYWORDS: Urban solid waste. Recyclable. Collectors. Infomal collect

\section{INTRODUÇÃO}

Os catadores, papeleiros, carroceiros, carrinheiros ou carapirás, como também são conhecidos, são as pessoas que buscam sua sobrevivência por meio da catação de materiais recicláveis existentes no lixo domiciliar, trabalhando nas ruas, aterros e lixões (MONTEIRO et al., 2001).

Segundo Romani (2004), estes "agentes ambientais" são responsáveis por boa parte dos materiais que chegam às indústrias recicladoras, reinserindo-os na cadeia produtiva como matériaprima secundária. O local de trabalho, os instrumentos utilizados e o nível organizacional são os fatores que diferenciam os catadores. Eles podem ser autônomos ou associados a organizações. Alguns catadores trabalham no local de descarrego dos caminhões de coleta nos lixões e aterros. Outros utilizam carrinhos para coletar os recicláveis nas ruas. Outros trabalham nas esteiras de triagem de resíduos, estes, em geral, são membros de alguma organização de catadores. Alguns catadores consideram sua função como uma atividade transitória, realizando-a apenas enquanto não encontram outro trabalho.

Existem milhares de crianças, adolescentes e adultos vivendo em lixões e aterros em todo o Brasil. São pelo menos 35 mil crianças e uma estimativa de 200 mil a 800 mil catadores trabalhando em todo o país (GRIMBERG, 2004).

De acordo com a Agência Brasil (2009), existem no país cerca de 600 cooperativas formais, que reúnem cerca de 40 mil catadores. A maioria dos catadores não está organizada, trabalha de forma individual. O maior contingente de catadores formais é encontrado na Região Sudeste, São Paulo e Minas Gerais lideram o ranking nacional de cooperativas de catadores.

O centro de informática da Usina Itaipu Binacional e o Movimento Nacional dos Catadores de Materiais Recicláveis (MNCR) desenvolveram em parceria o Cadastro Nacional de Catadores de Materiais Recicláveis, que é um sistema online que reúne dados que vão subsidiar a formulação de políticas públicas de inclusão dos catadores em todo o país. Quinhentas cooperativas de catadores de materiais recicláveis já estão incluídas no cadastro.

Em 1998 a United Nations Children's Fund (UNICEF) identificou a presença de 45 mil crianças trabalhando como catadores de resíduos em todo o Brasil, chamando a atenção do poder público e da sociedade para discutir a situação destas crianças, sujeitas a todo tipo de riscos. Assim, foi criada a campanha: "Criança no lixo nunca mais" e surgiu uma nova era na questão de saneamento ambiental/resíduos sólidos. Nas pesquisas nacionais de saneamento básico do Instituto Brasileiro de Geografia e Estatística (IBGE) de 2000 e 2010 foi incluído, como categorias do censo, o número de catadores existentes no Brasil, a questão dos lixões, da coleta seletiva e da educação ambiental (GRIMBERG, 2005).

Segundo Grimberg (2004), os catadores vêm intensificando sua mobilização, se organizando em níveis municipal, estadual e nacional, na perspectiva de garantir seus direitos em lei. Em 2001 ocorreu em Brasília o Congresso Nacional de Catadores que reuniu 1.500 catadores e 200 técnicos e 
agentes sociais. Este evento teve como resultado a "Carta de Brasília", documento que expressa a linha mestra da luta dos catadores em todo o país. Os Fóruns Lixo e Cidadania, com atuação em âmbito nacional, estadual e municipal também reforçam a necessidade de se instituir diretrizes e normas que possibilitem a plena integração dos catadores na cadeia do reaproveitamento de resíduos. Em 2003 foi criado o Comitê Interministerial de Inclusão Social dos Catadores de Lixo, cujos objetivos são a inclusão social dos catadores e a erradicação dos lixões.

Em 2003 ocorreu em Caxias do Sul/RS o $1^{\circ}$ Congresso Latino Americano de Catadores, reunindo pessoas do Brasil, Argentina e Uruguai, no qual os participantes assumiram compromissos através da Carta de Caxias do Sul (MNCR, 2003). Em 2005 ocorreu em São Leopoldo/RS o $2^{\circ}$ Congresso Latino Americano de Catadores, do qual participaram pessoas vindas de todas as regiões do Brasil e delegações da Argentina, Uruguai, Chile e Colômbia. Os participantes discutiram a realização dos compromissos assumidos no $1^{\circ}$ Congresso e assumiram novos desafios através da Declaração de São Leopoldo (MNCR, 2005).

As principais propostas dos catadores têm sido debatidas em vários eventos de caráter nacional, a citar: regulamentação da profissão; inclusão de leis trabalhistas; integração dos catadores avulsos e organizados em sistemas públicos municipais de reaproveitamento de resíduos; erradicação do trabalho de crianças em lixões e nas ruas; estímulo à criação de alternativas de geração de trabalho e renda e de moradia para as famílias que vivem nos lixões; investimento em programas de capacitação dos catadores para estruturação de cooperativas autônomas, para a geração de emprego e renda; criação de programas voltados para viabilizar a aquisição de veículos e equipamentos; cessão de áreas públicas para instalação das unidades de triagem de recicláveis; desenvolvimento de programas de fomento e subsídios para implantação de empresas de reciclagem de materiais, aumentando a demanda por estes materiais (GRIMBERG, 2007a, 2007b).

Durante muitos anos, o trabalho desenvolvido pelos catadores não era reconhecido pela sociedade. Além disso, muitos administradores públicos consideravam os catadores como "inimigos do sistema de limpeza urbana" por causarem problemas para a coleta de lixo. Com a organização da atividade esta situação começou a se reverter e aos poucos os catadores passaram a conquistar mais espaços e a ganhar mais visibilidade (ROMANI, 2004).

Nos últimos anos, no município de Passo Fundo/RS, assim como a quantidade de resíduos gerada, a quantidade de catadores também tem aumentado. Os catadores trabalham na área de disposição final de Resíduos Sólidos Urbanos (RSU) do município e, principalmente, nas ruas da cidade, coletando recicláveis em meio aos resíduos acondicionados pela população, rasgando os sacos plásticos, espalhando os resíduos nas lixeiras e nas ruas e atrapalhando o trânsito de pessoas e veículos com suas carroças ou carrinhos repletos de recicláveis. A forma de trabalho dos catadores tem gerado conflitos com a população, que muitas vezes não percebe o grande benefício ambiental desse trabalho, que desvia do aterro toneladas de resíduos que podem ser reaproveitados.

Desta forma, este trabalho tem como objetivo diagnosticar o processo de coleta e comercialização de resíduos recicláveis realizados pelos catadores da cidade de Passo Fundo.

\section{MATERIAL E MÉTODOS}

O município de Passo Fundo está localizado na região Norte do estado do Rio Grande do Sul e conta com uma população de 184.869 habitantes (IBGE, 2010), tem grande importância na região, atraindo anualmente milhares de pessoas em busca de recursos nas áreas de saúde, educação, prestação de serviços, emprego e moradia e sediando diversos eventos artísticos, culturais e científicos.

A estrutura metodológica para o desenvolvimento deste trabalho foi dividida em 2 etapas, descritas a seguir: 


\section{Etapa 1: Quantidade de catadores, suas formas de trabalho e seu perfil socioeconômico}

Nesta etapa foram coletadas informações sobre quantidade, formas de trabalho e o perfil socioeconômico dos catadores na cidade. No mês de abril de 2010, foram entrevistados os responsáveis pelos Setores de Abordagem e de Atendimento Social da Secretaria da Cidadania e Assistência Social (SEMCAS) e os coordenadores da Cáritas Diocesana e Associação Beneficente Ensine a Pescar (ABEP), que auxiliam as organizações de catadores.

No mês de maio de 2010 foram visitadas as 6 organizações de catadores da cidade legalmente constituídas e foram aplicados formulários aos responsáveis por estas organizações.

No mesmo período, através de consultas aos presidentes das associações de moradores da cidade, foram identificados os bairros onde os catadores residem e, posteriormente, foram realizadas visitas aos locais com as maiores quantidades de catadores.

Para a determinação do perfil socioeconômico destes trabalhadores, nos meses de junho a dezembro, foram aplicados formulários a 150 catadores que voluntariamente aceitaram participar da pesquisa e receberam uma breve explanação sobre a mesma. Do total que participaram da pesquisa, 138 foram abordados nas ruas da cidade, escolhidos de forma aleatória, tanto na área central quanto nos bairros onde existem as maiores quantidades de catadores, pois nem todos eles trabalham na área central, e outros 12 foram abordados em duas organizações de catadores, COOTRAEMPO e AAMA. Para a definição do tamanho da amostra foi utilizado o critério adotado pelo IBGE, que determina que a amostra deva corresponder a $10 \%$ da população, estimada em 1.500 catadores.

\section{Etapa 2: Tipos, quantidades e destino dos resíduos recicláveis}

Dados sobre os tipos, as quantidades e o destino dos resíduos recicláveis coletados pelos catadores foram obtidos através de formulários aplicados aos responsáveis pelas suas organizações, aos catadores que trabalham nas ruas da cidade e, nos meses de junho a dezembro, aos 9 sucateiros do município que compram os materiais recicláveis destes trabalhadores, os quais foram identificados a partir do formulário aplicado aos catadores.

\section{RESULTADOS E DISCUSSÃO}

\section{Etapa 1: Quantidade de catadores, suas formas de trabalho e seu perfil socioeconômico}

O número de catadores em Passo Fundo tem aumentado nos últimos anos e, segundo um levantamento realizado pelos assistentes sociais da Secretaria da Cidadania e Assistência Social (SEMCAS) em 2005, estimou-se que existiam aproximadamente 1.500 catadores de recicláveis na cidade. Do total, 97\% trabalham de forma autônoma e apenas 3\% trabalham, de fato, em organizações.

A maioria dos catadores autônomos utiliza carrinhos puxados manualmente ou carroças de tração animal. Podem-se observar as más condições de segurança dos catadores, que não utilizam nenhum tipo de equipamento de proteção individual, como luvas e sapatos adequados e também dos cavalos, geralmente submetidos à sobrecarga ao transportar os resíduos recicláveis.

Os carrinhos e carroças de catadores que trafegam na parte central da cidade geram muitos transtornos à população agravando os problemas de congestionamento do trânsito, além disso, a maioria não possui equipamentos de segurança, como sinaleiras e retrovisores, podendo causar acidentes principalmente quando trafegam a noite.

Pode-se observar nas ruas da cidade um número significativo de crianças e adolescentes que trabalham sozinhos ou acompanham seus pais na catação de resíduos recicláveis. De acordo com o coordenador do Núcleo de Abordagem da SEMCAS, em 2009, 146 crianças e adolescentes em situação de trabalho infantil foram abordadas nas ruas de Passo Fundo, dentre estes, 60\% estavam trabalhando com catação. 
As crianças e adolescentes abordados são encaminhados à rede de serviços assistenciais da secretaria, entre eles o Programa de Erradicação do Trabalho Infantil (PETI), que compreende um conjunto de ações que visam à retirada de crianças e adolescente com idade inferior a 16 anos da prática do trabalho precoce. O programa busca o desenvolvimento integral de crianças e adolescentes, oportunizando o acesso a escola formal, saúde, alimentação, esporte, lazer, cultura, profissionalização, bem como a convivência familiar e comunitária. Aproximadamente 100 crianças e adolescentes participam do programa que ocorre em 2 turnos, inversos ao turno escolar. O tempo de permanência no programa varia de acordo com a situação de cada participante, sendo que muitos são encaminhados posteriormente para outros programas da secretaria como Bombeiro Mirim e Cidadão Aprendiz. O programa tem seus méritos, mas não é suficiente, pois não abrange todas as crianças envolvidas com trabalho precoce.

Os dados a seguir foram coletados a partir dos formulários aplicados aos catadores e mostram que a maioria dos catadores autônomos trabalha 6 dias por semana, em dois turnos, manhã e tarde, coletando vários tipos de materiais recicláveis (plástico, papel, metal e outros) na região central da cidade. Destes, $68,3 \%$ utilizam carrinhos puxados manualmente, $25,4 \%$ utilizam carroças de tração animal e $6,3 \%$ utilizam outros equipamentos.

A maioria destes trabalhadores realiza duas viagens por dia e estoca os materiais em suas residências, onde é feita a separação de acordo com o tipo de material, até atingir um volume considerável para ser vendido posteriormente para sucateiros da cidade, que emprestam as bolsas (big bags) para o acondicionamento dos materiais que são recolhidos geralmente a cada 15 dias, nas residências destes catadores. De acordo com estes trabalhadores, praticamente não há concorrência de preços entre os sucateiros, sendo que a escolha entre um ou outro se dá em função da proximidade de suas residências.

Também existem catadores que trabalham apenas um turno e utilizam o outro para a separação dos materiais. Os que vendem os materiais diariamente para os sucateiros e os que coletam apenas um material específico, como papelão, por exemplo. A maioria não coleta vidros e nem embalagens longa vida, pois os preços de venda são baixos.

Quanto aos catadores que trabalham em organizações, existem na cidade 6 associações/cooperativas legalmente constituídas, ou seja, que possuem estatuto e CNPJ, a maioria apoiada por duas entidades beneficentes, Cáritas Diocesana e Associação Beneficente Ensine a Pescar (ABEP).

A Cáritas Diocesana juntamente com outras entidades lançou em 2007 o Projeto TransformAção, que desenvolve ações de capacitação de catadores e de estruturação e acompanhamento a associações e/ou cooperativas de recicladores para realização de coleta seletiva. As organizações de catadores da cidade são listadas a seguir:

\section{1- Cooperativa Mista de Produção e Trabalho dos Empreendedores Populares da Santa Marta (COOTRAEMPO)}

Esta cooperativa foi fundada pela Sociedade Cultural, Recreativa e Beneficente São João Bosco (SOCREBE) em 2005, que cedeu o pavilhão localizado na Vila Santa Marta e os equipamentos. No momento a Cáritas Diocesana acompanha o trabalho das catadoras. Atualmente 14 catadoras trabalham na cooperativa, que possui comodato do pavilhão, prensa e caminhão, que pertencem a SOCREBE, e empréstimo de uma picotadeira de papel que pertence a um dos sucateiros da cidade, que compra recicláveis da cooperativa. As trabalhadoras utilizam EPIs fornecidos pelo projeto TransformAção em parceria com uma empresa privada da cidade. As contas mensais de água e luz, cerca de $\mathrm{R} \$ 160,00$, as despesas mensais com combustível, cerca de $\mathrm{R} \$ 600,00$, e o salário do motorista, $\mathrm{R} \$ 650,00$, assim como eventuais manutenções de equipamentos são pagas pela cooperativa. As trabalhadoras recebem proporcionalmente aos dias trabalhados, cerca de $\mathrm{R} \$ 400,00$ mensais. 


\section{2- Associação Amigos do Meio Ambiente (AAMA)}

Em 2007, com a iniciativa do projeto TransformAção, teve início a construção do pavilhão de reciclagem em uma área cedida pela Prefeitura Municipal na Vila Popular. A associação foi formada em 2008 e começou a operar em janeiro de 2009. Inicialmente eram 14 catadoras, hoje são apenas 6. A associação possui comodato do pavilhão, que pertence ao projeto TransformAção. Esta associação recebeu como doação uma picotadeira de papel e adquiriu uma prensa. $\mathrm{O}$ caminhão utilizado para a coleta dos materiais pertence à Prefeitura. A associação também coleta e acondiciona óleo de cozinha em tanque devidamente credenciado junto a SMAM. As catadoras trabalham com EPIs fornecidos pelo projeto TransformAção em parceria com uma empresa privada da cidade. As contas mensais de água e luz, cerca de $\mathrm{R} \$ 130,00$, são pagas pela associação, assim como eventuais manutenções de equipamentos. As trabalhadoras recebem proporcionalmente aos dias trabalhados. Todas têm a mesma jornada de trabalho e recebem o mesmo valor, cerca de $\mathrm{R} \$ 300,00$ mensais.

\section{3- Associação de Recicladores União da Vitória (AREVI)}

Esta associação foi fundada em 2002, a partir do acompanhamento da Associação de Apoio a Estudantes (ADAE), que trabalha com recursos vindos do exterior. Atualmente é acompanhada pelo Projeto TransformAção. O galpão de reciclagem, que será utilizado pela associação em regime de comodato, já está sendo construído na Vila Bom Jesus com recursos oriundos de parcerias entre os governos federal e municipal. Atualmente a associação conta com 11 catadores que trabalham individualmente coletando materiais recicláveis com carrinhos nas ruas da cidade e acondicionam os materiais em casa.

\section{4- Associação de Recicladores da Vila Donária (Recidonária)}

Esta associação foi fundada no início de 2010 com o apoio da Associação Beneficente Ensine a Pescar (ABEP). Conta com a participação de 12 catadores que atualmente trabalham de forma individual coletando materiais recicláveis com carrinhos nas ruas da cidade. $\mathrm{O}$ galpão de reciclagem, que será utilizado pela associação em regime de comodato, já está sendo construído na Vila Donária, também com recursos oriundos de parcerias entre os governos federal e municipal.

\section{5- Associação dos Catadores do Parque Bela Vista (Recibela)}

A Cáritas Diocesana propôs para a Prefeitura a criação de uma associação com os cerca de 20 catadores que catavam materiais recicláveis no aterro sanitário do município. No final de 2009 a associação foi formada com a participação de aproximadamente 60 catadores, todos moradores do Loteamento Parque Bela Vista. Existe um convênio entre esta associação e a Prefeitura, a qual é responsável pelo repasse de recursos públicos e pagamento de contas de luz, água e manutenção dos equipamentos da usina de reciclagem. Esta associação é atualmente constituída por cerca de 20 catadores. No início de julho de 2010, os associados começaram a trabalhar nas instalações da usina de triagem de resíduos sólidos localizada no aterro sanitário. Os catadores trabalham em 2 turnos, das 8:00 às 14:00 e da 14:00 às 20:00, e 4 pessoas trabalham a noite na prensagem dos materiais. Estima-se que eles separem cerca de $30 \%$ de materiais recicláveis do total dos resíduos sólidos domiciliares coletados no município, e estima-se que cada catador receba cerca de $\mathrm{R} \$ 600,00$ mensais. 


\section{6- Associação Passo Fundense de Papeleiros}

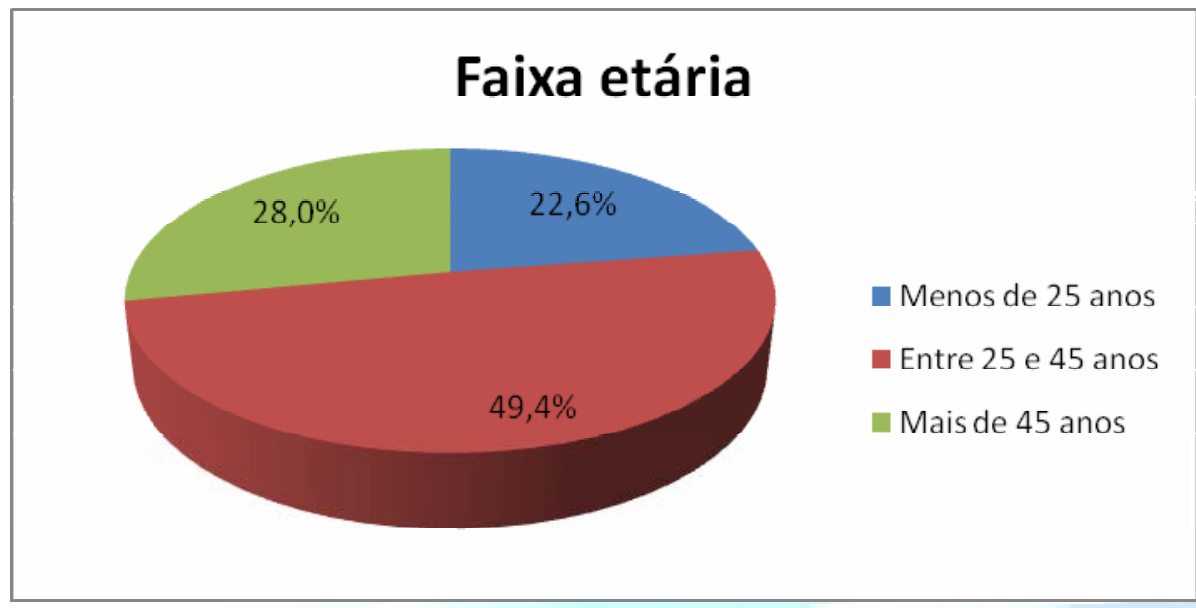

Figura 1. Faixa etária dos catadores de Passo Fundo

Esta associação foi fundada em 1988 no bairro Cohab I (atual Edmundo Trein) em um pavilhão emprestado pela iniciativa privada. Atualmente esta associação, conta apenas com um catador trabalhando em um pavilhão emprestado pelo Governo do Estado localizado no Bairro Industrial. A prensa utilizada também é emprestada. Esta associação recebe materiais de cerca de 20 catadores que trabalham com carrinhos doados por empresas privadas, porém eles atuam de forma autônoma.

\section{Perfil socioeconômico dos catadores}

O perfil socioeconômico dos catadores de recicláveis de Passo Fundo demonstra que 48\% dos catadores são do sexo feminino e $52 \%$ são do sexo masculino. Em pesquisas realizadas por Kirchner et al. (2009) em uma cidade da Fronteira-Oeste do estado do Rio Grande do Sul e por Bosi (2008) em 4 cidades do estado do Paraná, os homens prevaleceram, com 64\% e 60\% respectivamente.

Os resultados quanto à distribuição por faixa etária podem ser vistos na Figura 1.

Nota-se que quase metade dos catadores (49,4\%) possuem entre 25 e 45 anos e que uma parcela significativa $(22,7 \%)$ é de jovens que possuem de 14 a 25 anos, diferente do que foi observado na cidade da Fronteira-Oeste do RS, onde 52,2\% dos catadores possuem idade entre 25 e 45 anos e 47,8\% de 45 a 65 anos (KIRCHNER et al., 2009).

Quanto ao estado civil dos catadores, os resultados encontram-se na Figura 2. Observa-se que $37,4 \%$ dos catadores são solteiros, enquanto que 53,3\% são casados. Na cidade da FronteiraOeste do RS, 52\% dos catadores são solteiros e 40\% são casados (KIRCHNER et al., 2009). 


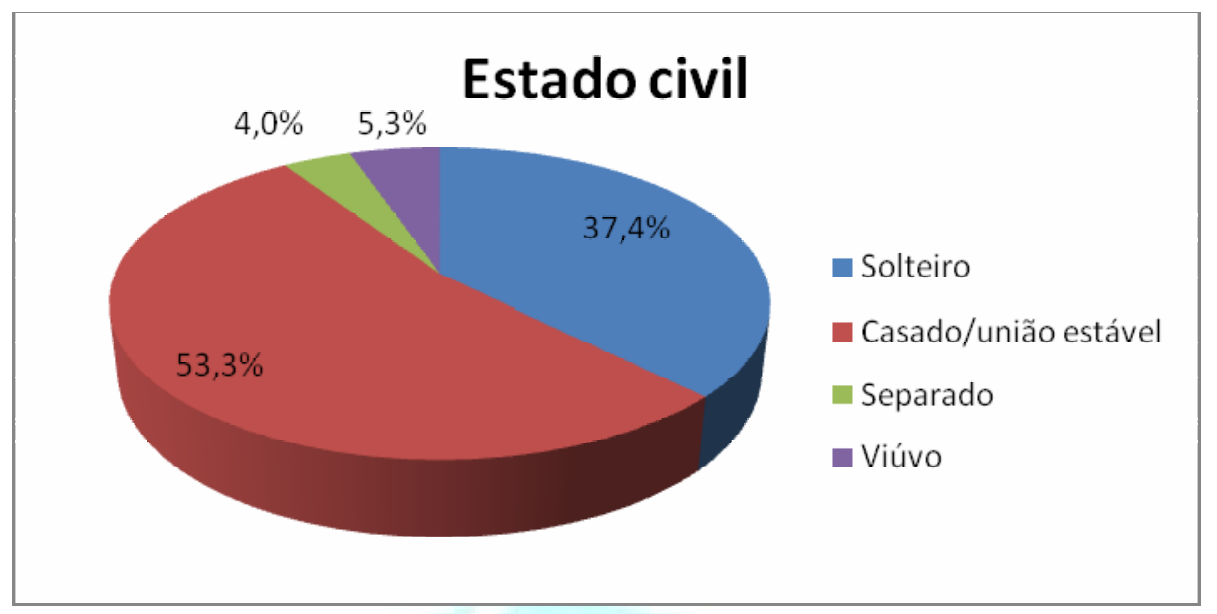

Figura 2. Estado civil dos catadores de Passo Fundo

Os resultados quanto ao número de dependentes dos catadores podem ser vistos na Figura 3. Destaca-se que aproximadamente $55 \%$ dos catadores possuem 3 ou mais dependentes.

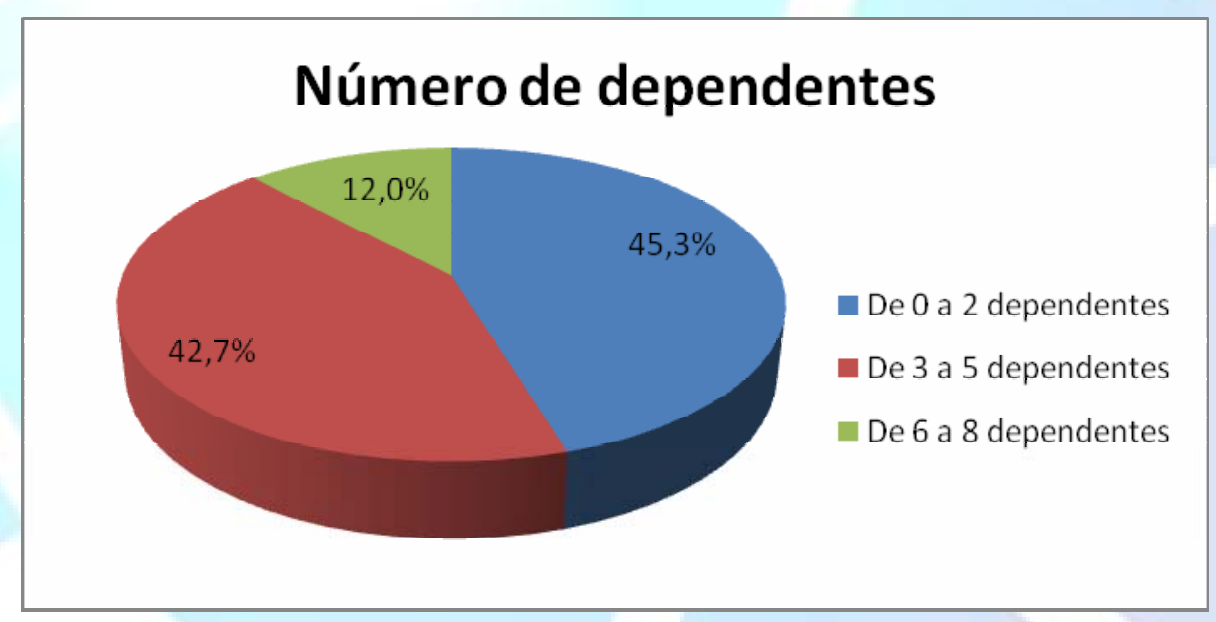

Figura 3. Número de dependentes dos catadores de Passo Fundo

Os catadores geralmente são trabalhadores desempregados que, por sua condição social e baixa escolaridade, não encontram lugar no mercado formal de trabalho. Os dados referentes à escolaridade dos catadores são apresentados na Figura 4.

Observa que quase $1 / 4$ dos catadores (24\%) são analfabetos. A baixa escolaridade igualmente foi observada em trabalhos anteriores, realizados por Magera (2003), Bosi (2008) e Kirchner et al. (2009). 


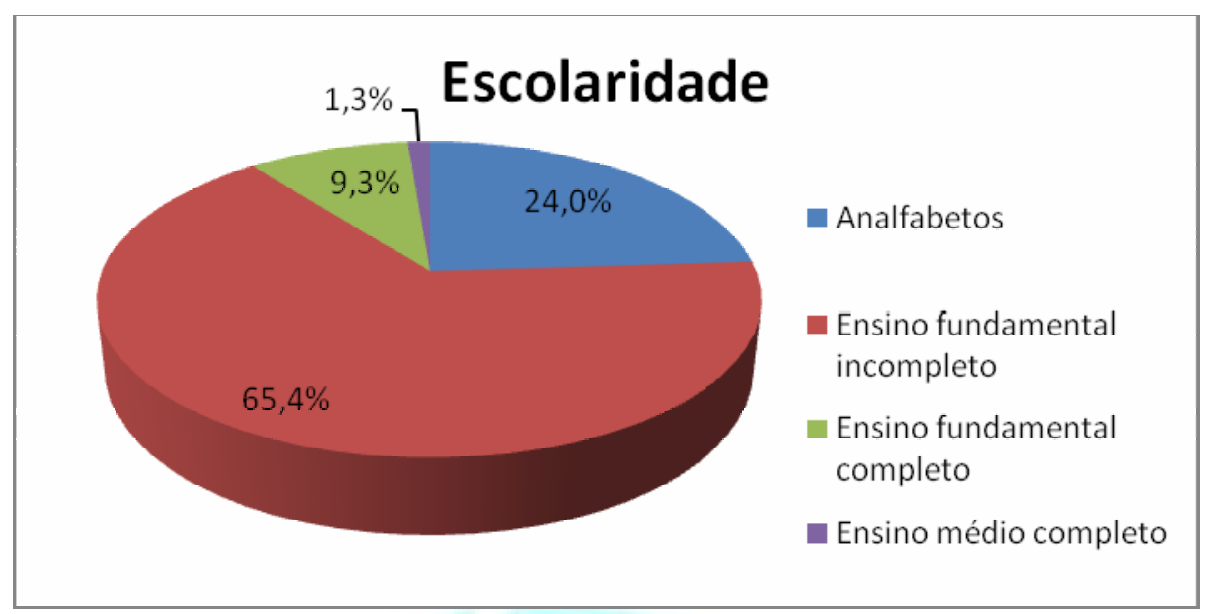

Figura 4. Escolaridade dos catadores de Passo Fundo

A maioria dos catadores tem a catação como única forma de renda e $92 \%$ declararam que recebem mensalmente menos de um salário mínimo ( $\mathrm{R} \$ 545,00)$, como pode ser visto na Figura 5.

Observou-se que os catadores que recebem mensalmente acima de R\$ 500,00 são aqueles que realizam 3 ou 4 viagens por dia e são predominantemente do sexo masculino. No estudo realizado por Bosi (2008), a maioria dos catadores entrevistados $(71,4 \%)$ também recebe renda inferior ao salário mínimo.

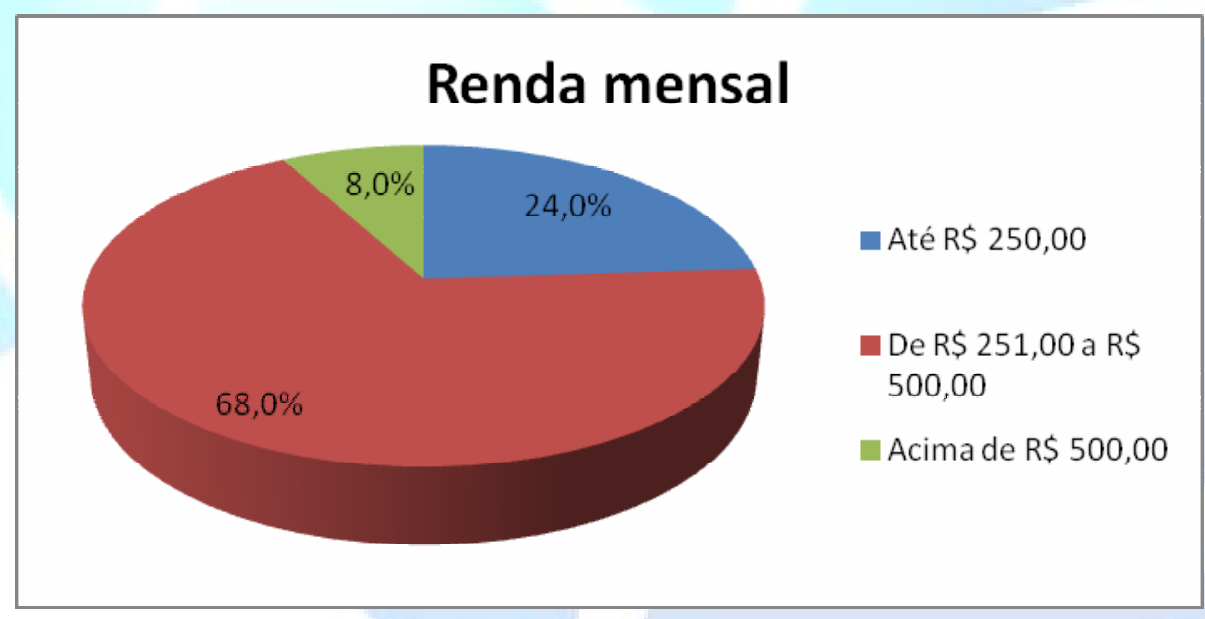

Figura 5. Renda mensal dos catadores de Passo Fundo

Foi possível perceber uma alta rotatividade ocupacional por parte dos catadores, sendo que, a maioria deles desempenha esta função somente enquanto não tem emprego formal. $O$ tempo de trabalho dos catadores é apresentado na Figura 6. 


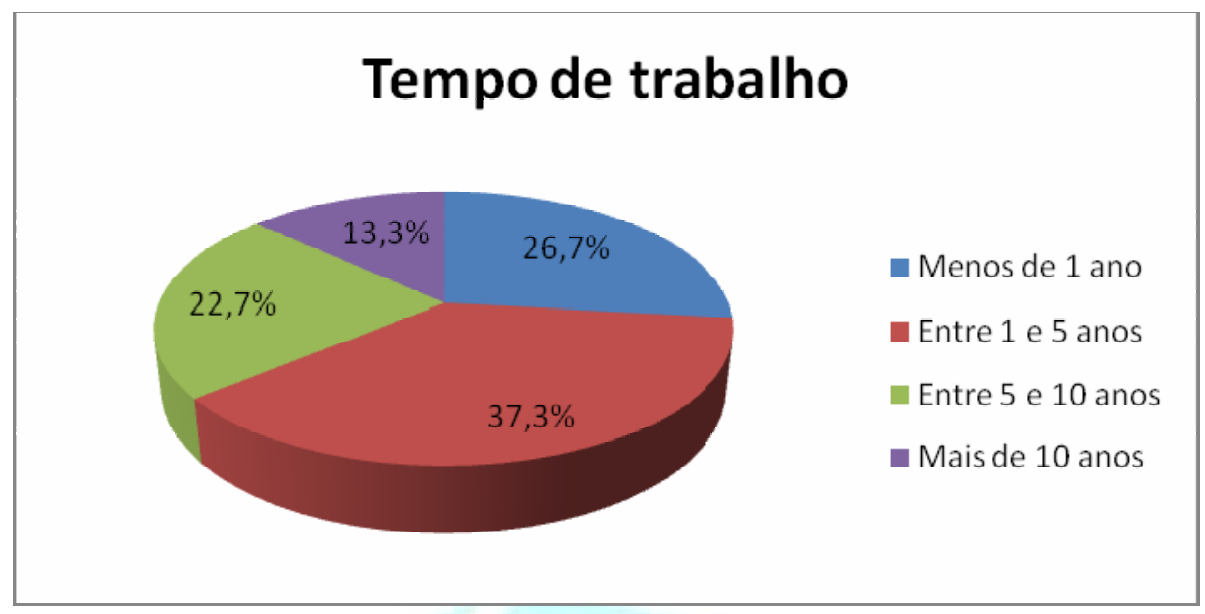

Figura 6. Tempo de trabalho dos catadores de Passo Fundo

Destaca-se que 36\% destes trabalhadores desempenham esta função há mais de 5 anos. Resultados semelhantes foram encontrados em pesquisa realizada por Kirchner et al. (2009) na cidade da Fronteira-Oeste do RS, na qual 58,3\% dos entrevistados atuam como catadores há menos de 5 anos e cerca de $30 \%$, de 5 a 10 anos.

A partir do levantamento realizado com os presidentes de associações de moradores do município foi possível identificar os bairros onde estes trabalhadores residem. Foram registradas presença de catadores em 55 bairros da cidade, sendo que em 21, existem mais de 10 catadores por bairro. O mapa da cidade mostrando o número de catadores de recicláveis por bairro e a localização das organizações pode ser visto na Figura 7.

A maior parte dos catadores reside na periferia da cidade, nos bairros de população de baixa renda e em áreas invadidas. Durante as visitas a estes bairros observou-se que a maioria deles vive em situação de extrema pobreza, em casas construídas com restos de materiais de construção e lonas, sem infraestrutura e saneamento básico. 


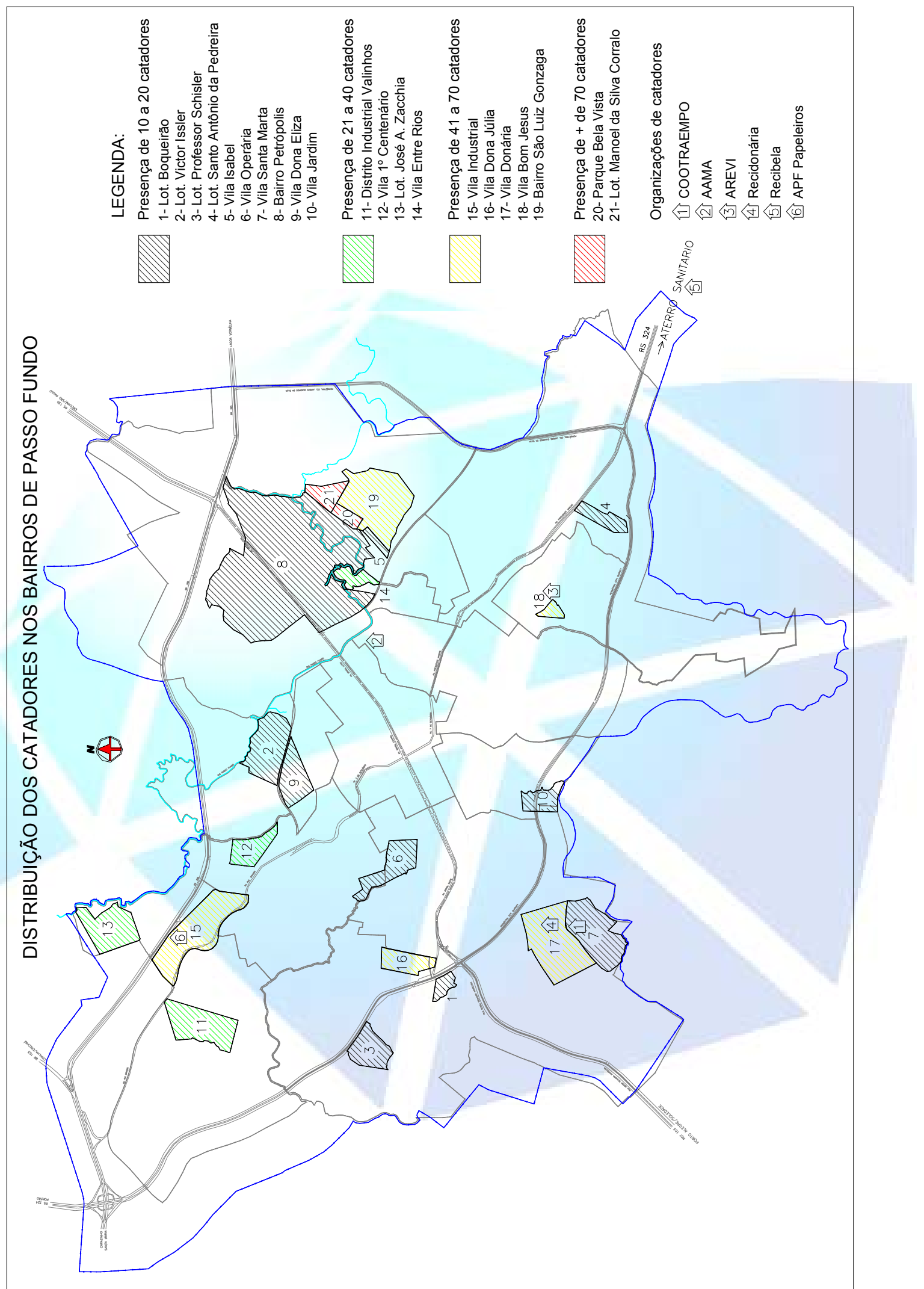

Figura 7. Mapa da distribuição dos catadores nos bairros de Passo Fundo e localização das organizações Fonte: Adaptado do mapa oficial da cidade de Passo Fundo (PASSO FUNDO, 2009) 


\section{Etapa 2: Tipos, quantidades e destino dos resíduos recicláveis}

AAMA e COOTRAEMPO são as únicas organizações de catadores que possuem pavilhão de reciclagem e vendem os materiais recicláveis em nome das organizações. A Recibela, que recém iniciou o trabalho como associação, ainda não tinha efetuado nenhuma venda até dezembro de 2010, quando este artigo foi finalizado. Nas demais organizações, cada catador comercializa os materiais recicláveis de forma autônoma.

A AAMA possui aproximadamente 110 pontos de coleta de recicláveis e óleo de cozinha usado. Esta associação comercializa cerca de 10 toneladas de recicláveis em média 600 litros de óleo de cozinha usado, que é utilizado para fabricação de combustível. A COOTRAEMPO coleta materiais recicláveis em aproximadamente 150 pontos da cidade e comercializa mensalmente cerca de 35 toneladas de materiais recicláveis.

Conforme o formulário aplicado aos catadores, estima-se que cada um colete mensalmente, em média, $800 \mathrm{Kg}$ de materiais recicláveis. Considerando a existência de 1.500 catadores, cerca de 1.200 toneladas de recicláveis seriam coletadas mensalmente por estes trabalhadores.

A COOTRAEMPO, a AAMA e a grande maioria dos catadores que trabalham de forma autônoma vendem os materiais recicláveis para 9 sucateiros da cidade. As quantidades de recicláveis comercializadas mensalmente por estes sucateiros podem ser vistas na Tabela 1.

Sabe-se que a quantidade de recicláveis comercializada mensalmente pelos sucateiros é superior a 405 toneladas, visto que não foi possível determinar a quantidade comercializada pelos dois maiores sucateiros da cidade.

Existem sucateiros de menor porte, que apenas recebem os materiais dos catadores e revendem para outros sucateiros mais estruturados. São apenas pontos de recebimento de produtos, fazendo com que, o preço pago aos catadores seja menor, pois quanto maior o número de atravessadores até a indústria, menor o preço pago no início do processo, isto é, a quem coleta estes materiais.

Tabela 1 - Quantidades de recicláveis comercializadas pelos principais sucateiros da cidade

\begin{tabular}{c|c|c|c}
\hline Sucateiro & Endereço (bairro) & $\begin{array}{c}\text { Quantidade de material } \\
(\mathbf{t} / \mathbf{m e ̂ s})\end{array}$ & $\begin{array}{c}\text { Quantidade comprada de } \\
\text { catadores }\end{array}$ \\
\hline $\mathrm{A}^{*}$ & Cruzeiro & - & - \\
\hline $\mathrm{B}^{*}$ & Vera Cruz & - & - \\
\hline $\mathrm{C}$ & Petrópolis & 200 & $80 \%$ \\
\hline $\mathrm{D}$ & São Luiz Gonzaga & 90 & $100 \%$ \\
\hline $\mathrm{E}$ & Ivo Ferreira & 50 & $70 \%$ \\
\hline $\mathrm{F}$ & Entre Rios & 25 & $100 \%$ \\
\hline $\mathrm{G}$ & Cruzeiro & 20 & $10 \%$ \\
\hline $\mathrm{H}$ & Independente & 15 & $50 \%$ \\
\hline I & Jardim América & 5 & $50 \%$ \\
\hline Total & \multicolumn{3}{|c}{} \\
\hline
\end{tabular}

*Não forneceram informações

Os catadores separam e classificam os materiais recicláveis de diversas maneiras. Destacase, que quanto mais puro e limpo o material, maior será o preço de venda.

Papel, papelão e plástico são vendidos pelos sucateiros para empresas no Rio Grande do Sul, como Bento Gonçalves, Caxias do Sul, Getúlio Vargas, Montauri e Encantado e, principalmente, para empresas de Santa Catarina, Paraná e São Paulo. Garrafas e potes de vidro inteiros são vendidos para pequenos produtores locais e todo vidro e metal coletado na cidade são comprados por um único sucateiro que não informou o destino destes materiais. 


\section{CONCLUSÕES}

O número de catadores na cidade é significativo e apenas 3\% trabalham de forma organizada, em associações ou cooperativas. A maioria vive em situação de extrema pobreza, trabalha em condições precárias, expostos a riscos de acidentes e contaminação. Como vivem em bairros na periferia, estes trabalhadores têm que percorrer diariamente grandes distâncias para realizar a catação na área central da cidade e os carrinhos e carroças utilizadas por eles atrapalham o trânsito de pessoas e veículos.

Os catadores que trabalham de forma autônoma não conseguem comercializar os recicláveis diretamente com as empresas recicladoras e têm que vender os materiais para os sucateiros, que separam e prensam estes materiais agregando valor ao produto. $\mathrm{O}$ fato das empresas recicladoras localizarem-se em outros municípios e estados aumenta o custo com o transporte, reduzindo ainda mais o preço pago aos catadores. Para as organizações de catadores, os preços de comercialização são melhores, devido à escala e à regularidade de produção.

A administração pública municipal de Passo Fundo e a sociedade, de maneira geral, têm se omitido em relação aos catadores, ignorando o grande benefício ambiental resultante desta atividade, que desvia do aterro sanitário toneladas de resíduos que podem ser reaproveitados e reciclados. Durante o ano de 2010 a Prefeitura incentivou a formação de organizações de catadores, permitindo que uma delas iniciasse seu trabalho na usina de triagem do município e licitando dois galpões de reciclagem que já estão em construção. Apesar destas iniciativas, ainda há muito que fazer para melhorar as condições de vida e trabalho dos catadores.

A falta de uma coleta seletiva bem estruturada dificulta o trabalho destes trabalhadores que precisam abrir os sacos de resíduos para coletar os recicláveis que, como estão misturados com a matéria orgânica, têm o preço de venda reduzido ou nem podem ser aproveitados.

Este artigo traz contribuições ao conhecimento do processo de coleta e comercialização de resíduos recicláveis realizado por catadores na cidade de Passo Fundo. Os dados obtidos poderão subsidiar o planejamento de políticas públicas e a elaboração do Plano Municipal de Gestão Integrada de Resíduos Sólidos Urbanos.

\section{AGRADECIMENTOS}

Os autores agradecem a todas as entidades e organizações pela disponibilidade das informações prestadas e ao Programa de Pós-Graduação em Engenharia (PPGEng) da Universidade de Passo Fundo, que possibilitaram essa pesquisa.

\section{REFERÊNCIAS}

AGÊNCIA BRASIL. Sistema online reúne dados sobre catadores de materiais recicláveis de todo país. Publicado em 18/08/2009. Disponível em < http://www.rts.org.br/noticias/destaque-1/>. Acesso em 30 abr. 2010.

BOSI, A. P. A Organização capitalista do trabalho "informal": o caso dos catadores de recicláveis. Revista Brasileira de Ciências Sociais, São Paulo, v. 23, n. 67, p.101-191, 2008.

GRIMBERG, E. A Política Nacional de Resíduos Sólidos: a responsabilidade das empresas e a inclusão social. Instituto Pólis. 2004. Disponível em $<$ http://www.polis.org.br /artigo interno .asp? codigo=35 $>$. Acesso em 24 abr. 2010. 
GRIMBERG, E. Reciclar, coletar ou jogar fora? Instituto Pólis. 2005. Disponível em < http://www.polis.org.br/artigo interno.asp?codigo=93>. Acesso em 24 abr. 2010.

GRIMBERG, E. Abrindo os sacos de "lixo": um novo modelo de gestão de resíduos está em curso no país. Instituto Pólis. 2007a. Disponível em $<$ http://www.polis.org.br /artigo_interno.asp?codigo=176 $>$. Acesso em 24 abr. 2010.

GRIMBERG, E. Política Nacional de Resíduos Sólidos: o desafio continua. Instituto Pólis. 2007b.

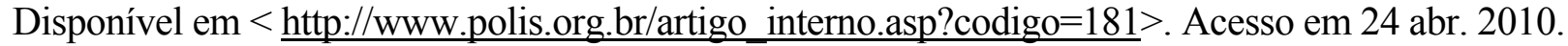

IBGE - INSTITUTO BRASILEIRO DE GEOGRAFIA E ESTATISTICA. Censo 2010. Disponível em

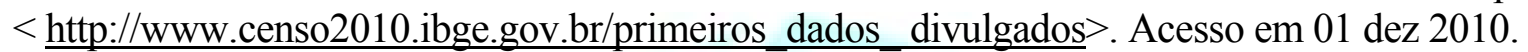

KIRCHNER, R.M; SAIDELLES, A.P.F; STUMM, E.M.F. Percepções e perfil dos catadores de materiais recicláveis de uma cidade do RS. Revista Brasileira de Gestão e Desenvolvimento Regional, Taubaté, v. 5, n. 3, p.221-232, 2009.

MAGERA, M. Os empresários do lixo: um paradoxo da modernidade. Campinas: Átomo. 2003.

MNCR. Site do Movimento Nacional dos Catadores de Recicláveis. Carta de Caxias do Sul. 2003. Disponível em $<$ http://www.mncr.org.br/box 1/principios-e-objetivos/carta-de-caxias-do-sul $>$. Acesso em 07 maio 2010.

MNCR. Site do Movimento Nacional dos Catadores de Recicláveis. $2^{\circ}$ Congresso Latino Americano de Catadores. 2005. Disponível em $<$ http://www.mncr.org.br/box_1/principios-eobjetivos/ii-congresso-latino-americano-de-catadores-as $>$. Acesso em 07 maio 2010.

MONTEIRO, J.H.P; FIGUEIREDO, C.E.M; MAGALHÃES, A.F; MELO, M.A.F; BRITO, J.C.X; ALMEIDA, T.P.F; MANSUR, G.L. Manual de Gerenciamento Integrado de Resíduos Sólidos. Rio de Janeiro: Instituto Brasileiro de Administração Municipal (IBAM) e Secretaria Especial de Desenvolvimento Urbano da Presidência da República (SEDU/PR), 2001.193p.

ROMANI, A. P. O poder público municipal e as organizações de catadores. Rio de Janeiro: IBAM./DUMA/CAIXA, 2004. 72p.

PASSO FUNDO. Site do município. Disponível em $<$ http://www.pmpf.rs.gov.br/secao.php?p $=158 \& \mathrm{a}=3>$. Acesso em 14 nov. 2009. 